\title{
ACANTHOMATOUS AMELOBLASTOMA- A CASE REPORT
}

Rajshekhar Jewargikar, S. S. Inamdar, V. L. Pattankar, Viral B. Laheru
1. Professor. Department of Pathology, M.R. Medical College, Gulbarga, Karnataka, India.
2. Professor. Department of Pathology, M.R. Medical College, Gulbarga, Karnataka, India.
3. Professor \& HOD. Department of Pathology, KBN Medical College, Gulbarga, Karnataka, India.
4. Post Graduate. Department of Pathology, M.R. Medical College, Gulbarga, Karnataka, India.

\section{CORRESPONDING AUTHOR}

Dr. Rajshekhar Jewargikar, Professor, Department of Pathology, M. R. Medical College, Sedam Road, Gulbarga- 585105, Karnataka, India. E-mail: sai.drrsj@gmail.com Ph: 00919916912789

ABSTRACT: Ameloblastoma is the most common clinically significant odontogenic tumor of the gnathic arches. The majority of ameloblastoma occurs in the posterior mandible with a wide variety of radiological and clinical presentation. The tumor arises from the enamel organ or its progenitor cell lines, resulting in a development of soft tissue component of the odontogenic tumor without production of any calcified product.

KEY WORDS: Ameloblastoma, acanthomatous.

INTRODUCTION: Ameloblastoma is a benign tumor, accounting for $1 \%$ of all the tumors of the jaw and $18 \%$ of odontogenic tumors. Acanthomatous ameloblastoma is a rare variant of follicular ameloblastoma with squamous metaplasia. Here with we are presenting a case of acanthomatous ameloblastoma.

CASE REPORT: A 35year female presented with swelling in the right side of the ramus of mandible measuring $2.5 \times 2 \mathrm{~cm}$. X-ray- unilocular cystic swelling.

GROSS: examination revealed unilocular cystic mass with a rough hemorrhagic external surface. Cut section- Wall thickened grey white, luminal surface is ragged with punctate hemorrhages (fig-01).

MICROSCOPY: H \& E stained sections show Islands of odontogenic epithelium within a fibrous stroma. The islands are composed of basophilic columnar cell at periphery, exhibiting reverse polarization of nuclei away from the connective tissue with vacuolization (fig-02). The central area is less cellular, edematous, resembling stellate reticulum. There are areas showing squamous epithelial metaplasia (fig-03).

DISCUSSION: Ameloblastomas are derived from the ameloblasts or dental lamina. The WHO has classified several histopathologic subtypes. Acanthomatous ameloblastoma is a rare variant of follicular ameloblastoma with squamous metaplasia and even keratinization are seen in the stellate reticulum area. It has a $26 \%$ recurrence rate. The differential diagnosis for this entity includes ameloblastic fibroma, squamous cell carcinoma and basal cell carcinoma. Treatment consists of adequate tumor removal including margin of uninvolved tissue with long term follow up. 
CONCLUSIONS: Acanthomatous Ameloblastoma is a very rare tumor. Timely recognition and surgical intervention of ameloblastomas may improve treatment outcomes and may also diminish morbidity and recurrence.

\section{REFERENCES:}

1. Walke,V.A, Munshi,M.M, Raut.W.K, Bobahate.S.K; Cytological diagnosis of acanthomatous ameloblastoma; journal of cytology; 2008;25(2):62-64.

2. Brooks J.K., Al-Mubarak H, Ribera.M.J., Cohen.P.D., Ross.D.S., Scheper.M.A. Diminutive, interradicular "hybrid" desmoplastic/acanthomatous ameloblastoma;. Quintessence International; 2010: 41(3);209-212.

3. Lester D. R. Thompson; Benign neoplasm of the gnathic bone. In : Head and neck pathology, a volume in the series, foundations in diagnostic pathology; Churchill livingstone; 474-491.

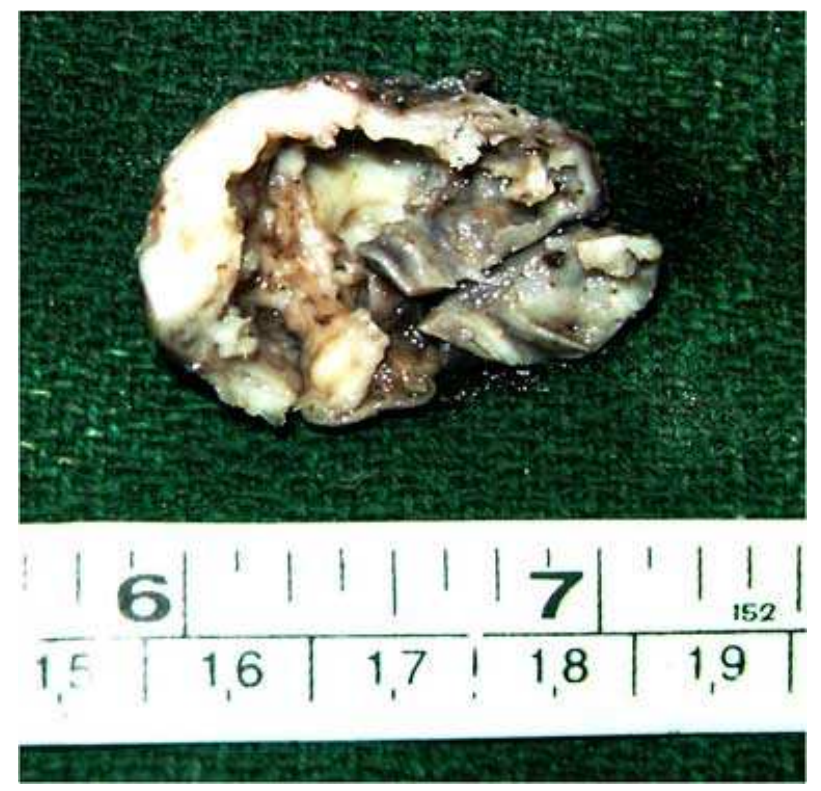

Gross picture of cut section showing thickened wall with area of hemorrhages.

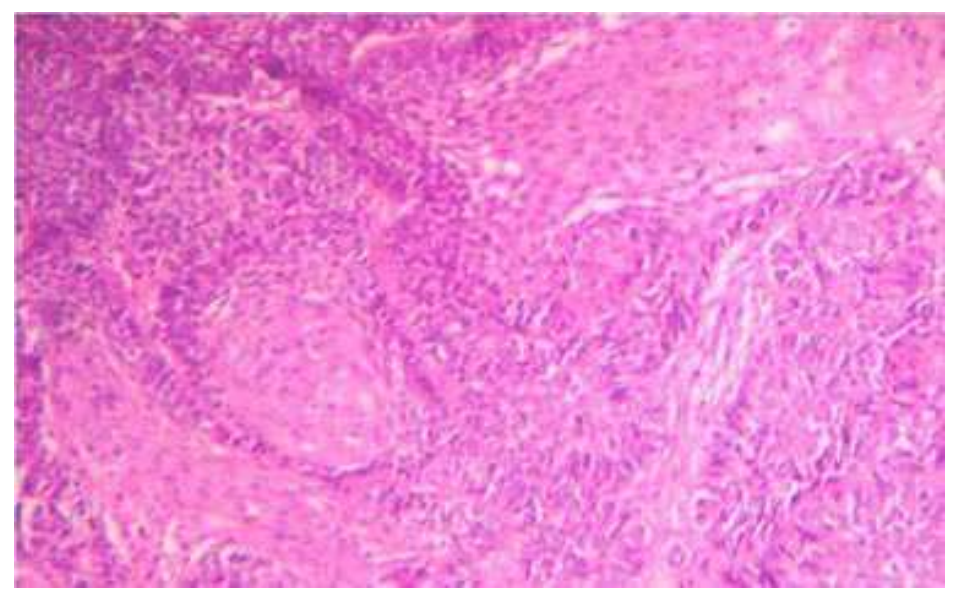

H\&E stained section shows basophilic columnar cells with reverse polarisation of nuclei 10X. 


\section{CASE REPORT}

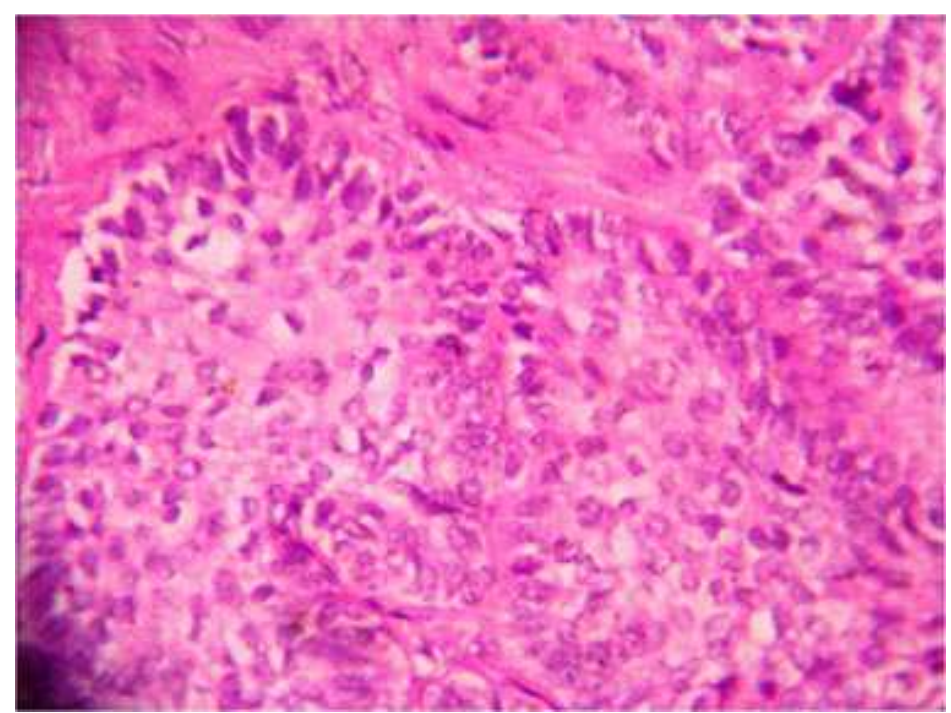

H\&E stained section showing ameloblastic epithelium with squamous metaplasia 40X 